\title{
Huntington's disease in Chinese: a hypothesis of its origin
}

\author{
C M Leung, Y W Chan, C M Chang, Y L Yu, C N Chen
}

\begin{abstract}
The period prevalence (1984-91) of Huntington's disease (HD) in Hong Kong Chinese was 3.7 per million population. HD patients in Mainland China and Hong Kong showed similar hereditary pattern, clinical and pathological features as in the West. Chinese HD patients were male predominant with a younger age of onset and death. Their ancestral origin could be traced mostly to the coastal provinces of China. It is proposed that Chinese HD patients may have a European origin and share the same gene pool as their white counterparts.
\end{abstract}

\section{(尹 Neurol Neurosurg Psychiatry 1992;55:681-684)}

The prevalence of HD in the West varies from 40-100 per million population with pockets of high density in some areas. ${ }^{1}$ The origin of most cases in white populations can be traced to their ancestors who left England, France or the Netherlands in the 17 th or 19 th century. ${ }^{2-6}$ The European origin of the HD in Australia, North and South America is undisputed. ${ }^{7}$

Literature on HD in the East is limited due to the relative rarity of the disease. In Japan, the first case was reported in 1935 by Kishimoto. The prevalence was $4 / 10^{6}$ in the Aichi province, approximately one-tenth that of the Western countries. ${ }^{8}$ The negative assortive marriage, incomplete penetrance (penetrance estimated to be 0.94 ) and above all low detection rate were reasons cited as an explanation of the low prevalence rate. More recent data suggested an even lower figure of $1 \cdot 1 / 10^{6}$ in the Ibaraki Prefecture. ${ }^{9}$ The annual death rate from HD in Japan was estimated to be $0 \cdot 15$ per million population, again about onetenth of the figure in the West. ${ }^{10}$ Isolated cases were also reported from the Indian subcontinent but the lack of systematic survey precluded reliable estimation of the prevalence. ${ }^{113}$

The data on Chinese are even more scarce and have been published mainly in the Chinese literature. In Hong Kong, only two reports with seven cases have been published so far ${ }^{14} 15$ and the prevalence has not been studied. This paper reviews all reports on HD patients from Mainland China and Hong Kong, and discusses a hypothesis for the origin of $\mathrm{HD}$ in Chinese.

\section{Methods}

Reports of HD in Chinese published in major neurology and psychiatry journals of Mainland China and the West from 1950-90 were reviewed. Only index cases were included. A systematic survey of $\mathrm{HD}$ was conducted at all major neurology and psychiatry units in Hong Kong. Public announcement through newsletters to all local doctors was followed by personal contact. Each patient was examined by a neurologist and a psychiatrist. The diagnosis of HD was based on the presence of a positive family history, insidious, progressive chorea and disorder of voluntary movement, cognition, and often psychiatric disturbance. ${ }^{16}$ Laboratory investigations were performed to aid the diagnosis. These included blood counts and smear, serum copper and caeruloplasmin, blood biochemistry, EEG and CT of brain. Caudate atrophy on CT supported the diagnosis. Conditions which may mimic HD including Wilson's disease, senile chorea, benign hereditary chorea and neuroacanthocytosis were therefore excluded. The hereditary pattern, ancestral origin, clinical and pathological features were reviewed. The sex distribution, mode of parental transmission and age of onset were analysed with chi-square and Wilcoxon tests.

\section{Results}

Up to 1990, a total of 69 index patients have been reported in Mainland China and Hong Kong. ${ }^{1417}{ }^{30}$ The recent survey in Hong Kong collected another 20 cases, making a total of 89. Without an epidemiological investigation, we could not discover the prevalence of HD in Mainland China. In Hong Kong, 20 Chinese HD patients from 11 families were identified between 1984-91. As the average Chinese population during this period was 5.44 million, the period prevalence was 3.7 per $10 .^{6}$ Six patients had died by 1991 . There were therefore 14 patients in the 5.55 millions Chinese population of Hong Kong at 1991, hence the point prevalence of 2.5 per $10 .^{\circ}$

The first HD patients in Mainland China and Hong Kong were reported by Wang ${ }^{18}$ in 1959 and Singer ${ }^{15}$ in 1962 respectively. There were all together 63 males and 26 females reported with a ratio of $2 \cdot 42: 1$ (table). The male predominance was statistically significant, $\mathrm{X}^{2}=15.3, \mathrm{df}=1, \mathrm{p}<0.001$ (chi-square test). Of the 89 index patients who came from 63 families, a positive family history was obtained in 72. Paternal transmission was found in 50 patients $(69.4 \%)$ and maternal in $22(30.5 \%)$ with statistically significant difference, $\mathrm{X}^{2}=10 \cdot 89, \mathrm{df}=1, \mathrm{p}<0.001$ (chi- 
Table Huntington's disease in mainland China and Hong Kong

\begin{tabular}{|c|c|c|c|c|c|}
\hline \multicolumn{2}{|l|}{ Author } & $\begin{array}{l}\text { Number of } \\
\text { Index cases }\end{array}$ & $\begin{array}{l}\text { Sex } \\
M: F\end{array}$ & $\begin{array}{l}\text { Transmission } \\
\text { Pat:Mat }\end{array}$ & $\begin{array}{l}\text { Number of } \\
\text { Pedigrees }\end{array}$ \\
\hline \multicolumn{6}{|c|}{ Mainland China } \\
\hline Wang & 1959 & 2 & $1: 1$ & $1: 0$ & 2 \\
\hline Yin & 1963 & 1 & $0: 1$ & $0: 1$ & $\overline{1}$ \\
\hline Liu et al & 1980 & 2 & $1: 1$ & $2: 0$ & 2 \\
\hline $\mathrm{Li}$ and Luan & 1980 & 4 & $2: 2$ & $3: 1$ & 1 \\
\hline $\mathrm{Li}$ & 1981 & 6 & $4: 2$ & $3: 3$ & 3 \\
\hline Liu et al & 1982 & 8 & $7: 1$ & $3: 3$ & 8 \\
\hline Shen et al & 1983 & 3 & $3: 0$ & $0: 1$ & 3 \\
\hline $\mathrm{Li}$ et al & 1985 & 29 & $21: 8$ & $15: 7$ & 24 \\
\hline Chen et al & 1987 & 2 & $1: 1$ & $2: 0$ & 1 \\
\hline Ha et al & 1988 & 2 & $1: 1$ & $2: 0$ & 1 \\
\hline Dai and Gao & 1988 & 4 & $3: 1$ & NA & 4 \\
\hline Zhao et al & 1989 & 2 & $2: 0$ & $2: 0$ & 1 \\
\hline Shao et al & 1989 & 1 & $1: 0$ & $1: 0$ & 1 \\
\hline Total & & 66 & $47: 19$ & $34: 16$ & 52 \\
\hline \multicolumn{6}{|l|}{ Hong Kong } \\
\hline Singer & 1962 & 3 & $1: 2$ & $2: 1$ & 1 \\
\hline Present series & 1991 & 20 & $15: 5$ & $14: 5$ & 10 \\
\hline \multicolumn{2}{|c|}{$\begin{array}{l}\text { Mainland China and } \\
\text { Hong Kong }\end{array}$} & 89 & $63: 26$ & $50: 22$ & 63 \\
\hline
\end{tabular}

NA = not available

Pat $=$ paternal

Mat = maternal tively. Patients with either paternal or maternal transmission showed no statistical difference in the age of onset of HD (mean 36.9 vs 38.5 years, $p=0.73$ ). The duration of illness from onset to death ranged from one to 14 years (mean 8.2 years) with the age of death ranging from 29 to 60 years (mean 43.0 years). Of the 73 patients whose clinical details were available, all exhibited progressive chorea and cognitive impairment and $21(29 \%)$ presented initially with psychiatric symptoms. Four patients of juvenile onset type (age of onset ranging from four to ten) were also reported. ${ }^{1529} 30$ This constituted $4.5 \%$ of the total 89 index patients. Three of the four juvenile patients presented with akinetic rigidity and two were a monozygotic twin pair concordant for HD. All four had paternal transmission. Chromosomal abnormality of parallel translocation between chromosome number 2 and 21 was reported in a brother-sister pair both with the disease, with unknown significance. ${ }^{27}$ Cognitive assessment, ${ }^{28}$ EEG and CT, ${ }^{1520262729}$ necropsy $^{15192026}$ and treatment response, showed similar findings to those in the West.

Of the $62 \mathrm{HD}$ families whose ancestral origin could be traced, $45(73 \%)$ and $17(27 \%)$ families came from coastal and non-coastal

Figure

*= reporting centre; $X \boldsymbol{f}=$ Xinjiang; $Z L=$ Zilin province

$\begin{array}{ll}\text { Costal province } \\ \text { GD } & \text { Guangdong } \\ \text { HeB } & \text { Hebei } \\ \text { FS } & \text { fiangsu } \\ \text { LL } & \text { Liaoling } \\ \text { SD } & \text { Shangdong } \\ \text { Zf Zhejiang } \\ \text { Subtotal }\end{array}$

$\begin{array}{cl}\text { Number of cases } & \text { Non-coastal province } \\ 8 & \text { AF ANFEI } \\ 10 & \text { HN Henan } \\ 22 & \text { HuB Hubei } \\ 1 & \text { SX Shanxi } \\ 3 & \text { SC Sichuan } \\ 1 & \text { Subtotal } \\ 45(73 \%) & \end{array}$

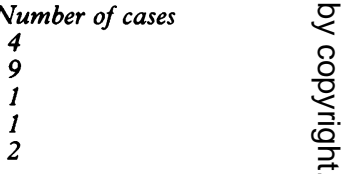

age of onset ranged from 16 to 54 (mean 34.8 years). The mean values for males and females were 38.7 and $34 \cdot 1$ years respecautosomal dominant. The most distant family history could be traced back five generations. $^{31}$

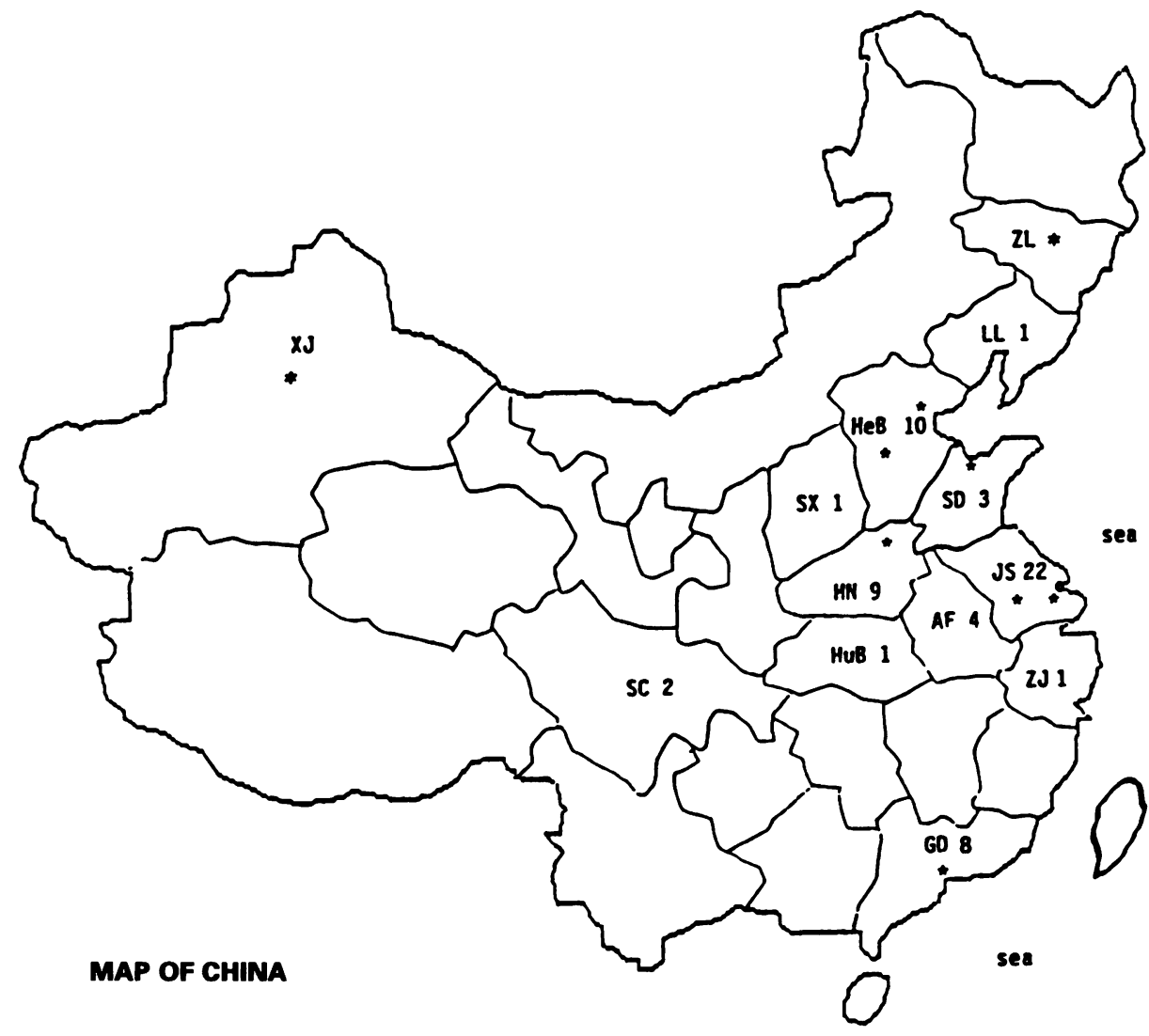


provinces respectively (figure). Most of them clustered at the coastal provinces of Jiangsu $(35 \%)$, Hebei $(16 \%)$ and Guangdong $(13 \%)$. Two inland provinces, Henan and Anfei, which also reported a fair number of cases, are located just adjacent to Jiangsu and Hebei. The location of reporting centres more or less overlapped with the origin of patients reported (figure), but one family reported from Xinjiang near the western border of China were originally from Jiangsu.

\section{Discussion}

The lack of systematic survey of HD in Mainland China precludes precise estimation of its prevalence. This study in Hong Kong Chinese shows that the period prevalence (1984-91) of the disease was 3.7 per $10^{6}$ and the point prevalence at 1991 was 2.5 per $10^{6}$, figures that approximate that reported in Japan. ${ }^{9}$ Since our study is not a door-to-door population survey, our prevalence data are probably a reasonable though not a full estimate.

The mode of inheritance was invariably autosomal dominant although positive family history could not be obtained in $19 \%$. Since new mutation is rare (less than $0.1 \%$ ) and penetrance high in $\mathrm{HD},{ }^{32}$ the lack of positive family history could best be explained by illegitimacy, denial of the illness, or the chorea in the parents was mild and escaped detection. Internal migration due to war and natural disasters certainly made case-tracing more difficult. An interesting feature in Chinese HD patients, which differs from western findings, was the male predominance both in sex distribution and disease transmission. Paternal transmission was found in two thirds of our patients who had positive history. One possible explanation is sampling bias against the female sex who have a lower social status in the Chinese society, thus attracting less social and medical attention.

The mean age of onset ( 34.8 years) and age of death (43.0 years) were significantly younger, and the mean duration of illness $(8 \cdot 2$ years) were shorter than figures in the West. ${ }^{44-37}$ Difference in defining the onset of illness, the standard of medical care and the variation of virulence in different ethnic groups are possible explanations. The favourable influence of maternal factors in the onset of $\mathrm{HD}^{33} 38$ was not borne out in our current study, as HD patients with either paternal or maternal transmission showed no difference in the age of onset.

The concentration of cases in the coastal region of China, namely the Jiangsu and Hebei Provinces, is an interesting phenomenon. One explanation may be that these are the more prosperous areas with better medical service and thus a better chance of case discovery and reporting. However, other equally rich but non-coastal provinces, for example, Sichuan, have reported much fewer cases. Furthermore, the Jiangsu family reported in Xinjiang at the western border of China could be more than a coincidence.
This peculiar geographical distribution leads us to postulate that HD in Chinese is not indigenous but has a European origin. In Hong Kong $^{31}$ and Taiwan, ${ }^{39}$ the oldest families that could be traced were five and four generations respectively. If 25 years is taken as one generation for procreation, the oldest case was probably born in the mid 1800 s, when China was invaded by the West. The treaty of Nanking was signed in 1841 with the West gaining access to five ports, including Shanghai in Jiangsu Province, ${ }^{40}$ where the Chinese HD patients are concentrated. This date paralleled the arrival of the first HD patients at Tasmania and Venezuela. In contrast to countries like the United States and Venezuela, the disease in China has remained relatively localised in coastal regions. The "ultra-stable" infrastructure of the Chinese culture, hostility of the inland population towards Westerners, and young age of onset and death of Chinese HD patients would help limit extensive spread of the disease.

Racial admixture with white populations may explain the origin of HD in Japanese whose situation is analogous to the Chinese. They traded with the Dutch in the Edo era starting in mid 17th century and other Westerners since the Meiji era in the 19th century. In areas with more foreign contacts, for example, Aichi Province, there is a higher prevalence of HD than neighbouring areas. ${ }^{8}$ The Japanese HD gene has recently been found to be similar to its white counterparts in DNA marker studies. ${ }^{41}$ This preliminary analysis of Chinese HD patients provides primi facie evidence for our hypothesis. To substantiate it, further family tracing and genetic studies including human leucocyte antigen profiles and DNA analysis are required and currently in progress. Should the case be proven, further insight into this rare but tragic disease may be gained.

Abstract presented at the Joint Annual Scientific Meeting of the Australian Association of Neurologists and Hong Kong Neurological Society, May 1991, Hong Kong.

1 Kurtzke JF. Huntington's disease: mortality and morbidity data from outside the United States. Adv Neurol data from ou

2 Vessie PR. On the transmission of Huntington's chorea for 300 years - the Bures family group. 7 Nerv Ment Dis 1932;76:553-73.

3 Barbeau A, Coiteux C, Trudeaux JG, Fullum G. La choree de Huntingdon chez les Canadiens Français. Union Medicale de Canada 1964;93:1178.

4 Hayden MR. Huntington's chorea. New York: SpringerVerlag, 1981

5 Brothers CRD. The history and incidence of Huntington's chorea in Tasmania. Proc $R$ Aust Coll Physicians 1949; 4:48-50.

6 Negrette A. Corea de Huntington. Maracaibo, Venezuela: University of Zulia, 1985.

7 Heathfield KWG. Huntington's chorea: a centenary review. Postgrad Med f 1973;49:32-45.

8 Kishimoto K, Nakamura M, Sotokawa Y. Population genetics study of Huntington's chorea in Japan. Annu Rep Res Inst Environ Med 1957;9:195-211.

9 Kanazawa I. On the prevalence rate of Huntington's disease in Ibaraki prefecture. Annual Report of the Research in Ibaraki prefecture. Annual Report of the Research

10 ImaizumiY. Mortality rate of Huntington's disease in Japan: secular trends, marital status, and geographical variations. secular trends, marital status, and geograph
fapanese $\mathcal{f}$ of Hum Genet 1989;34:169-78.

11 Singh A, Singh S, Jolly SS. Huntington's chorea-a report of 4 new pedigrees from Punjab. Neurology (Bombay)
ong 1959.7:7-8.

12 Khosla SN, Arora BS. Huntington's chorea-a clinical study. F Assoc Physicians India 1973;21:247-50.

13 Shiwach RS, Lindenbaum RH. Prevalence of Huntington's disease among UK immigrants from the Indian Subcon- 
tinent. Br F Psychiatry 1990;157:598-9.

14 Singer $K$. Huntington's chorea in the Chinese. $B M F$ 1962;2:1311-2.

15 Leung CM, Chan YW, Yu CS. Huntington's disease in Hong Kong. Neurosci Lett Suppl 1990;40:S30

16 Folstein SE. The diagnosis of Huntington's disease. In Folstein SE, eds. Huntington's disease. A disorder of families. Baltimore: The John Hopkins University Press, 1989:125-48.

17 Wang ZX. A report of two cases of Huntington's chorea. Chinese f Neurol Psychiat 1959;6:384-5.

18 Yin ZX. A case report of Huntington's chorea. Chinese $\mathcal{F}$ Neurol Psychiat 1963;7:57.

19 Hou MD, Chen Y, Chen MQ. Huntington's chorea. Chinese f Neurol Psychiat 1964;8:129-31.

20 Liu LD, Xu YX, Liu BB. 2 reported cases of chronic progressive chorea. Chinese $\mathcal{f}$ Nerv Ment Dis 1980; progres

$21 \mathrm{Li}$ WS, Luan SL. A study of a family of Huntington's chorea. Chinese f Nerv Ment Dis 1980;6:292-4.

$22 \mathrm{LiWS}$. A report of 6 cases of Huntington's chorea. Chinese f Nerv Ment Dis 1981;14:151.

23 Liu DK, Tan YJ, Zhang XG, et al. Chronic progressive chorea. Chinese $\mathcal{f}$ Nerv Ment Dis 1982;8:193-7.

24 Shen WJ, Zhang ZY, Huang ZW. A report of 3 cases of Huntington's chorea. Chinese $f$ Neurol Psychiatry 1983;16:148.

$25 \mathrm{Li} \mathrm{ZH}$, Deng RK, Chen $\mathrm{Z}$, et al. Huntington's chorea. Chinese f Neurol Psychiat 1985;18:21-3.

26 Chen CL, Liu C, Wu J, et al. An autopsy study of Huntington's disease in a pair of brother and sister. Chinese $f$ Neurol Psychiat 1987;20:369-71.

$27 \mathrm{Ha} \mathrm{ZY.} \mathrm{A} \mathrm{family} \mathrm{study} \mathrm{of} \mathrm{Huntington's} \mathrm{chorea} \mathrm{with}$ chromosomal abnormality. Chinese f Nerv Ment Dis chromosomal
28 Dai SD, Gao GY. Huntington's chorea and dementia. Chinese $f$ Neurol Psychiat 1988;21:363.

29 Shi FY Z CH. Dou LP. Case report of rigidity type of Huntington's chorea. Chinese f Nerv Ment Dis 989;15:114.

30 Zhao XZ, Yu CL, Chang LF. Juvenile onset Huntington's disease in a monozygotic twin pair. Chinese $\mathcal{f}$ Nerv Ment Dis 1989;15:377.

31 Chang CM, Yu YL, Wong MTH, et al. Huntington's disease in Hong Kong Chinese: clinical picture and pathology. (Submitted).

32 Shaw $M$, Caro A. The mutation rate to Huntington's chorea. $f$ Med Genet 1982;19:161-7.

33 Farrer LA, Conneally M. Predictability of phenotype in Huntington's disease. Arch Neurol 1987;44:109-13.

34 Brothers CRD. Huntington's chorea in Victoria and Tasmania. $\mathcal{F}$ Neurol Sci 1964;1:405-20.

35 Myers RH, Martin JB. Huntington's disease. Semin Neurol yers RH, Martin

36 Martin JB. Huntington's disease: new approaches to an old problem. Neurology 1984;34:1059-72.

37 Walker DA, Harper PS, Wells CEC, et al. Huntington's chorea in South Wales. A genetic and epidemiological tudy. Clin genet 1981;19:213-21.

38 Myers RH, Cupples LA, Schoenfeld M, et al. Maternal factors in onset of Hungtington's chorea. Am $\mathcal{f}$ Hum Genet 1985;37:511-23.

39 Tsuang MT. Huntington's chorea in a Chinese family. F Med Genet 1969;6:354-6.

40 Gou YT. An Outline History of Modern China. The Chinese University Press of Hong Kong, 1974.

41 Kanazawa I, Kondo I, Ikeda J, et al. Studies on DNA markers (D4S10 and D4S43/S127) genetically linked to markers (D4S10 and D4S43/S127) genetically linked to Huntington's disea 